\title{
White rice consumption and risk of type 2 diabetes: meta-analysis and systematic review
}

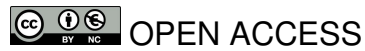

\author{
Emily A Hu research assistant ${ }^{1}$, An Pan research fellow ${ }^{1}$, Vasanti Malik research fellow ${ }^{1}$, Qi Sun \\ instructor in medicine ${ }^{12}$
}

${ }^{1}$ Department of Nutrition, Harvard School of Public Health, 655 Huntington Avenue, Boston, MA 02115, USA; ${ }^{2}$ Channing Laboratory, Department of Medicine, Brigham and Women's Hospital and Harvard Medical School, 181 Longwood Avenue, Boston

\begin{abstract}
Objectives To summarise evidence on the association between white rice consumption and risk of type 2 diabetes and to quantify the potential dose-response relation.

Design Meta-analysis of prospective cohort studies.

Data sources Searches of Medline and Embase databases for articles published up to January 2012 using keywords that included both rice intake and diabetes; further searches of references of included original studies.

Study selection Included studies were prospective cohort studies that reported risk estimates for type 2 diabetes by rice intake levels.

Data synthesis Relative risks were pooled using a random effects model; dose-response relations were evaluated using data from all rice intake categories in each study.

Results Four articles were identified that included seven distinct prospective cohort analyses in Asian and Western populations for this study. A total of 13284 incident cases of type 2 diabetes were ascertained among 352384 participants with follow-up periods ranging from 4 to 22 years. Asian (Chinese and Japanese) populations had much higher white rice consumption levels than did Western populations (average intake levels were three to four servings/day versus one to two servings/week). The pooled relative risk was 1.55 (95\% confidence interval 1.20 to 2.01 ) comparing the highest with the lowest category of white rice intake in Asian populations, whereas the corresponding relative risk was 1.12 (0.94 to 1.33) in Western populations ( $P$ for interaction $=0.038$ ). In the total population, the dose-response meta-analysis indicated that for each serving per day increment of white rice intake, the relative risk of type 2 diabetes was 1.11 (1.08 to 1.14) ( $P$ for linear trend<0.001).
\end{abstract}

Conclusion Higher consumption of white rice is associated with a significantly increased risk of type 2 diabetes, especially in Asian (Chinese and Japanese) populations.

\section{Introduction}

Humans have a long history of cultivating rice crops; rice was first domesticated approximately 8000 to 9000 years ago by people living in the region of the Yangtze River valley in China. ${ }^{1-3}$ Rice is now grown worldwide and provides food for more than half of the world's population, especially those living in some of the most populous countries, such as China, India, and Japan. Polished rice or white rice, which primarily consists of starch, is produced through a series of mechanised processes including hulling and milling, ${ }^{4}$ and it is the predominant type of rice consumed worldwide. ${ }^{5-7}$ Although the glycaemic index value of a specific white rice variety depends on the degree of processing, cooking time, and amylose content, the glycaemic index values of white rice are higher on average than those of whole grains. ${ }^{8}$ For example, the mean glycaemic index values were 64 (SD 7) for white rice, 55 (5) for brown rice, 41 (3) for whole wheat, and 25 (1) for barley in a previous meta-analysis. ${ }^{8}$ In addition, white rice is the primary contributor to dietary glycaemic load for populations that consume rice as a staple food. $^{57}$

In large scale human observational studies among various populations, diets with a high glycaemic index or glycaemic load were associated with increased risk of developing type 2 diabetes. ${ }^{7-11}$ A significant positive association between white rice consumption and risk of diabetes was observed among two cohorts of Chinese and Japanese women, ${ }^{57}$ although the association was not significant for Japanese men. ${ }^{5}$ Two investigations in Western populations with much lower consumption levels than Asian populations also generated mixed results. ${ }^{12} 13$ These studies were heterogeneous with respect to sample size, white rice intake levels, and other characteristics that may contribute to inconsistencies in the literature. In addition, whether any dose-response relation exists between 
white rice consumption and risk of diabetes is unknown. Therefore, we did a meta-analysis on all published prospective cohort studies evaluating white rice intake and incidence of type 2 diabetes and quantified dose-response relations between intake of white rice and risk of type 2 diabetes.

\section{Methods}

\section{Search strategy}

We did a literature search (up to January 2012) of Medline and Embase for prospective cohort studies examining the association between rice intake and risk of type 2 diabetes. The search terms were ("Diabetes Mellitus"[Mesh] OR "diabetes"[All Fields]) AND ("Oryza sativa"[Mesh] OR "rice" OR "grain") for Medline and ('diabetes'/exp OR diabetes) AND ('rice'/exp OR rice OR 'grain'/exp OR grain) for Embase. We supplemented this search with a manual search of references cited by selected articles. One investigator (QS) did this literature search.

\section{Study selection}

We applied the following inclusion criteria: prospective cohort study, patients with self reported prevalent diabetes excluded at baseline, and point estimates of relative risk with $95 \%$ confidence intervals or standard errors available or derivable. We excluded animal studies, clinical trials, cross sectional studies, case-control studies, reviews, commentaries, letters, and studies that examined other associations. We also applied a criterion of study quality that all included cohort studies should have a loss to follow-up rate below $20 \%$. Two investigators (EAH and AP) independently screened all studies by title or abstract and then by a full text evaluation. Any discrepancy between the two authors was solved by discussion with the senior investigator (QS).

\section{Data extraction}

We extracted the following information from each study: study's characteristics (study name, authors, year of publication, journal, study location, duration of follow-up, person time, and number of participants and incident cases), participants' characteristics (age and sex), exposure (rice intake levels for each category) and dietary assessment method, reproducibility and validity of assessment method, outcome (type 2 diabetes) ascertainment, and analysis strategy (statistical models, covariates included in the models, and risk estimates in each category). For studies that reported rice intake as servings per week or day, we converted it to grams per day by assuming that each serving was equivalent to $158 \mathrm{~g}$ of cooked rice. To convert raw rice intake levels to cooked rice consumption levels for Villegas et al's study, we multiplied raw intake levels by a factor of 2.5 .

Two investigators (EAH and AP) extracted data independently, and any discrepancies were resolved by discussion. For two studies that expressed data separately for men and women or included data from multiple cohorts, ${ }^{5}{ }^{13}$ we considered the analysis for each sex or cohort as an independent report and extracted data separately. As per our request, Hodge et al provided the number of cases and person years for each rice intake category in their study and confirmed that white rice accounted for the vast majority (approximately 95\%) of total rice consumption in their study (Allison Hodge, email communication). ${ }^{12}$ To assess the quality of included studies, we derived a score that summarised 15 aspects of each study, including study design, response rate, follow-up rate, follow-up time, exposure and outcome measurements, and statistical analysis (supplementary table A).

\section{Statistical analysis}

Hazard ratios (equivalent to relative risks in cohort studies) were used as the common measure of association in all studies except for those by Nanri et al and Hodge et al, which used logistic regression to model the association of interest. Because of the very low incidence of type 2 diabetes in these two studies (five year risk was $1.9 \%$ for Nanri et al's study and $1.2 \%$ for Hodge et al's study), we considered odds ratios to be relatively accurate estimates of the true relative risks. We further derived estimates of person time for Nanri et al's study by multiplying the number of participants by the follow-up time for each category of rice intake. We pooled all relative risks by using a random effects model comparing extreme categories of intake and set study weights to be equal to the inverse variance of each study's effect estimate. We produced forest plots to assess the multivariate adjusted relative risks and corresponding 95\% confidence intervals visually across studies. We evaluated heterogeneity of relative risks across studies by using the Cochrane Q statistic (we considered $\mathrm{P}<0.05$ to be indicative of statistically significant heterogeneity) and the $\mathrm{I}^{2}$ statistic. We did stratified analyses according to ethnicity (Asian versus Western). To evaluate potential interactions between rice intake and ethnicity, we used Altman et al's method to evaluate whether the pooled relative risks differed between different ethnic groups. ${ }^{14} \mathrm{We}$ also fitted a fixed effects model to examine the between group heterogeneity and used the $\mathrm{P}$ value for heterogeneity to evaluate the interactions. We used Begg funnel plots and Egger's tests to assess potential publication bias. ${ }^{15}$

To evaluate a potential non-linear dose-response relation, we first used a restricted cubic spline regression model (Stata RC_SPLINE command) with three knots to create spline variables that we subsequently used in our analysis to derive the generalised least squares trend estimation of pooled dose-response data (Stata GLST command). ${ }^{16}{ }^{17} \mathrm{We}$ then fitted another regression model without the spline terms. Lastly, we used the likelihood ratio test to examine the significance of any non-linearity by comparing the model with the linear term only and the model with both the linear and the cubic spline terms. This analysis used data from the relative risks and $95 \%$ confidence intervals, number of cases and person years, and median/mean of rice intake levels for each comparison group. Median intake levels for each rice consumption category were available in Nanri et al's study. ${ }^{5}$ For all other studies that did not provide such data, we calculated the average of the two extreme values of each comparison group to determine mean rice intake levels. For the highest consumption category, we assumed that the average consumption level was the cut-off point plus a $25 \%$ increment, which was largely consistent with Nanri et al's study. Because of unstable estimators in a random effects cubic spline model as a result of lack of power, we used a fixed effects model to evaluate the dose-response relation. We calculated absolute risk differences as background incidence ratex(relative risk-1).

We used Stata statistical software version 11.0 for all analyses. $\mathrm{P}$ values were two sided with a significance level of 0.05 .

\section{Results \\ Literature search}

Figure $1 \Downarrow$ shows results from the literature search and study selection process. We identified 825 articles from the Medline database and 2453 articles from the Embase database. After exclusion of duplicate records and studies that did not meet our inclusion criteria, 36 articles remained, and we further evaluated the full texts of these publications. Of these, we excluded five 
studies because they did not separate rice from other carbohydrate sources, 16 because no original data could be extracted (reviews, letters, or cross sectional studies), 10 that we deemed irrelevant, and one that had a loss to follow-up rate of $31.7 \% .^{18}$ Finally, four studies met the inclusion criteria and were included in the meta-analysis. A manual search of references cited by these studies did not yield new eligible articles. Among these four studies, Nanri et al's study examined men and women separately and Sun et al's report included data from three independent cohorts. Therefore, we included seven comparisons in the meta-analysis.

\section{Study characteristics}

Tables $1 \Downarrow$ and $2 \Downarrow$ show the characteristics of the included studies. All four studies were prospective cohort studies in participants who were free of self reported diabetes at baseline (total $n=352$ 384). Hodge et al's study further excluded any patients with diabetes whose date of diagnosis was before the study baseline even though they did not report having a diagnosis of diabetes at baseline interview. Among the participants, 13284 incident cases of diabetes occurred during follow-up periods ranging from four to 22 years. Two studies were done in Asian populations (China and Japan) and the other two studies in Western populations (the United States and Australia). Average rice intake levels varied dramatically across studies. For example, in the Chinese study the mean intake level of cooked rice was approximately four servings ( $625 \mathrm{~g}$ ) per day, whereas in the two studies done in the United States and Australia most (98\% for the US study and $71 \%$ for the Australian study) participants consumed less than five servings a week. In all studies, dietary intake was assessed by food frequency questionnaires, which were validated against multiple day diet records or 24 hour recalls. Moderate correlation coefficients of dietary intake of rice have been found (ranged from 0.53 to 0.66 ), supporting reasonably good validity of rice intake assessment in these studies. Results from our assessment of study quality showed that most studies achieved a score of 12 or above (the maximum score was 15) except for Hodge et al's study, which achieved a score of 7 (supplementary table A).

\section{White rice intake and risk of type 2 diabetes}

Figure $2 \Downarrow$ summarises the comparisons of the highest and lowest categories of white rice intake levels. Overall, the random effects model summarising all seven comparisons suggested a positive association; the pooled relative risk was 1.27 (95\% confidence interval 1.04 to 1.54 ), although significant heterogeneity was detected $\left(I^{2}=72.2 \%\right.$; Cochrane $Q$ test $\left.P=0.001\right)$. With stratification by ethnicity, the association was stronger for Asian populations (pooled relative risk 1.55, 1.20 to 2.01) than for Western populations $(1.12,0.94$ to 1.33$)$. In both strata, the $\mathrm{P}$ for heterogeneity was not significant $(\mathrm{P}=0.17$ and $\mathrm{P}=0.13)$. The difference in the pooled relative risks between these two groups reached statistical significance $(\mathrm{P}=0.038)$, suggesting an interaction between rice intake and ethnicity. Similarly, when we used a fixed effects model to examine between ethnic group heterogeneity, we found a significant $\mathrm{P}$ for heterogeneity $(\mathrm{P}<0.001)$. The funnel plot and Egger's test $(\mathrm{P}=0.30)$ did not suggest evidence of publication bias (supplementary figure $\mathrm{A}$ ).

\section{Dose-response relation between white rice intake and diabetes risk}

In a fixed effects cubic spline model that included all studies, we did not find evidence suggesting any non-linear relation between white rice consumption and risk of diabetes ( $\mathrm{P}$ for non-linearity $=0.51)($ fig $3 \Downarrow)$. For each serving per day increment of white rice consumption, the relative risk was 1.11 (1.08 to 1.14; $\mathrm{P}$ for linear trend $<0.001)$. Using the incidence rate of diabetes in the middle aged US population ( 15.2 cases/1000 population aged $45-64$ years), ${ }^{19}$ we estimated that 167 cases of diabetes per 100000 middle aged people would occur each year for each serving per day increase in consumption of white rice. (These estimates may underestimate the risk difference for Asian populations that are experiencing an accelerated incidence rate of diabetes. ${ }^{20}$ ) To illustrate this, we further plotted the incidence rate of diabetes by intake levels for each comparison category in Asian and Western populations (supplementary figure B).

\section{Secondary analysis}

We did several secondary analyses to examine the robustness of the primary results. Firstly, we evaluated a potential interaction by sex. Because Hodge et al's did not separate men from women in their analysis, we excluded this study in this secondary analysis. The association was more pronounced among women (pooled relative risk 1.46, 1.16 to 1.83 ) than men (1.08, 0.87 to 1.34 ) (supplementary figure C). Secondly, we excluded Hodge et al's study, which had a lower quality score than other studies and did not separate white rice from brown rice. This analysis yielded a pooled relative risk of $1.17(0.97$ to 1.42 ) comparing the highest and lowest categories in Western populations. The relative risk was 1.33 (1.09 to 1.63) for all populations, and a significant $\mathrm{P}$ for heterogeneity $(\mathrm{P}=0.006)$ was still present in this analysis. Lastly, when we included $\mathrm{Yu}$ et al's study among Chinese people living in Hong Kong, ${ }^{18}$ which was excluded from the primary analysis because of a high rate of loss to follow-up, we found similar associations; comparing the highest and the lowest categories, the pooled relative risk was 1.45 (1.11 to 1.89) for Asian populations and 1.24 (1.03 to 1.50$)$ for total populations.

\section{Discussion}

In this meta-analysis of prospective cohort studies, we found that higher white rice consumption was associated with a significantly elevated risk of type 2 diabetes. This association seems to be stronger for Asians than for Western populations. A dose-response analysis showed that each serving per day of white rice consumption was associated with an $11 \%$ increase in risk of diabetes in the overall population.

\section{Strengths and limitations}

Several caveats of this meta-analysis are worth discussing. Firstly, although the ethnicity stratified analysis did not show significant heterogeneity within each group, the limited number of studies may lead to diminished statistical power for detecting heterogeneity within each stratum. Secondly, although we included the results from only the fully adjusted models, because all individual studies were observational in nature the results of these studies may still be subject to residual confounding or other biases. Confounding by socioeconomic status is of particular concern because this is both a risk factor for type 2 diabetes and a predictor of rice consumption in Asian and Western populations. ${ }^{5} 7^{21-24}$ However, the US studies consisted of participants from the same professional background, so confounding by socioeconomic status was likely to be small. In addition, other studies controlled for indicators of socioeconomic status such as income and education. Nevertheless, residual confounding by socioeconomic status cannot be completely ruled out in these studies. Depending on 
the nature of uncontrolled or residual confounding, the associations seen in these individual studies and our meta-analysis could be biased in either direction. Large scale pooling projects, in which covariate adjustments and statistical analysis can be standardised, are needed to confirm the findings of this meta-analysis. Likewise, the dose-response relation could be more precisely modelled in such pooling projects.

Thirdly, all studies used food frequency questionnaires to assess levels of white rice intake. Although validation studies showed reasonable reproducibility and validity of self reported rice intake, measurement error is inevitable. Measurement error in assessment of exposure may lead to attenuation of true associations in a prospective study, especially when the exposure was assessed before disease assessment. Fourthly, although all studies excluded cases of self-reported diabetes at baseline, some undiagnosed cases may still be included in the analysis. However, the effect of such a bias is likely to be small. In the US studies, self reported diagnosis of diabetes was highly accurate; the Australian study further excluded any cases with a diagnosis date before baseline, even if they did not report diabetes at baseline interview; and in Asian studies, because rice is a staple food, substantial reduction of rice consumption after diagnosis of diabetes is unlikely. Lastly, we were unable to include brown rice in this meta-analysis or to evaluate the effects of substituting brown rice for white rice, because the association between brown rice and risk of diabetes was examined only in Sun et al's study. ${ }^{13}$

The strengths of this meta-analysis include the large sample size and long duration of follow-up of the included studies. In addition, most established risk factors for type 2 diabetes were adjusted for in the fully adjusted models in these studies. Moreover, inclusion of studies in both Asian and Western countries allowed us to investigate the dose-response relation on the basis of a wide spectrum of white rice intake levels.

\section{Results in relation to other studies}

Several potential mechanisms could explain the association between white rice consumption and risk of type 2 diabetes. Among Asian populations, which consume white rice as a staple food, white rice is the predominant contributor to dietary glycaemic load. For example, in women living in Shanghai, white rice accounted for $73.9 \%$ of dietary glycaemic load ${ }^{7}$; in Japanese women, white rice explained $58.5 \%$ of dietary glycaemic load. ${ }^{25}$ In a meta-analysis that pooled data from cohort studies primarily done in Western populations, dietary glycaemic load was consistently associated with increased risk of developing type 2 diabetes. ${ }^{26}$ Similarly, recent investigations in Chinese and Japanese populations also support the hypothesis that high dietary glycaemic load is associated with increased risk of diabetes. ${ }^{72} 27$ The relatively weaker association for Western populations seen in this meta-analysis may be due to the fact that white rice intake was much lower than in Asians and, therefore, was only a minor contributor to dietary glycaemic load. In addition, the glycaemic index values of various white rice varieties depend on several factors including amylose content, other botanical structures, and processing methods. ${ }^{828-30}$ The contribution of white rice to dietary glycaemic load may vary substantially, especially when consumption levels are low. Nonetheless, high intake of white rice may also lead to increased risk of diabetes through mechanisms other than its contribution to dietary glycaemic load. Compared with minimally processed whole grains such as brown rice, white rice has a lower content of many nutrients including insoluble fibre, magnesium, vitamins, lignans, phytoestrogens, and phytic acid, which are lost during the refining process. ${ }^{31}$ Some of these nutrients, especially insoluble fibre and magnesium, have been associated with lower risk of type 2 diabetes in prospective cohort studies. ${ }^{9}{ }^{10}$ 32-36 Thus, a high consumption of white rice may lead to increased risk of diabetes because of the low intake of beneficial nutrients, in addition to its higher glycaemic load. Meanwhile, more data are needed to shed light on whether the interaction by ethnicity is due simply to substantially different white rice intake levels or to other mechanisms.

Data on the association between brown rice intake and type 2 diabetes are limited. In Sun et al's work in Western populations, brown rice intake was associated with a modestly decreased risk of type 2 diabetes, and the substitution of brown rice or other whole grains for white rice was associated with a significantly lower risk of diabetes. ${ }^{13}$ Because Asian populations consume white rice almost exclusively, no data on the relation between brown rice and risk of diabetes are available in these populations. Nevertheless, a 16 week clinical trial in 76 Korean men showed that isocaloric replacement of white rice with whole grains and legume powder (composed of $66.6 \%$ whole grains, $22.2 \%$ legumes, $5.6 \%$ seeds, and $5.6 \%$ vegetables) led to significant reductions in serum glucose and insulin concentrations, whereas body weight remained unchanged. ${ }^{37}$ However, a recent study in Shanghai found that substituting brown rice for white rice for 16 weeks did not substantially affect metabolic markers in middle aged men and women, although high density lipoprotein cholesterol and diastolic blood pressure were significantly improved among people with diabetes through the brown rice intervention. ${ }^{38}$ More studies with larger sample sizes and longer durations of follow-up are warranted to examine the effects of substituting brown rice for white rice on risk of diabetes.

\section{Conclusions}

In summary, this meta-analysis suggests that higher white rice intake is associated with a significantly elevated risk of type 2 diabetes, especially among Asian populations. The recent transition in nutrition characterised by dramatically decreased physical activity levels and much improved security and variety of food has led to increased prevalence of obesity and insulin resistance in Asian countries. ${ }^{39}$ Although rice has been a staple food in Asian populations for thousands of years, this transition may render Asian populations more susceptible to the adverse effects of high intakes of white rice, as well as other sources of refined carbohydrates such as pastries, white bread, and sugar sweetened beverages. In addition, the dose-response relations indicate that even for Western populations with typically low intake levels, relatively high white rice consumption may still modestly increase risk of diabetes.

We thank Allison M Hodge and Ruby Yu for providing data for the meta-analysis.

Contributors: $\mathrm{EAH}, \mathrm{AP}$, and $\mathrm{QS}$ searched the literature and extracted data. QS had the idea for the analysis. VM, AP, and QS provided statistical expertise. EAH and AP analysed the data. EAH wrote the first draft of the manuscript. All authors contributed to the interpretation of the results and critical revision of the manuscript for important intellectual content and approved the final version of the manuscript. QS is the guarantor.

Funding: QS was supported by career development award K99HL098459 from the US National Heart, Lung, and Blood Institute. The funding sources had no role in study design; in the collection, analysis, and interpretation of data; in the writing of the report; or in the decision to submit the article for publication. The authors are not affiliated with the funding institutions. 


\section{What is already known on this topic}

The association between white rice consumption and risk of type 2 diabetes has been examined in both Asian and Western populations, but the findings are not entirely consistent across studies

The substantial difference in baseline rice intake levels between Asians and other populations for whom rice is not a staple food may contribute to the inconsistency of existing results

However, a systematic and quantitative summary of published studies to date is not available

\section{What this study adds}

Pooled data suggest that higher white rice consumption is associated with increased risk of developing type 2 diabetes in comparison with lower intake levels

This association is stronger for Asian (Chinese and Japanese) populations than for Western populations

Overall, there was a dose-response relation between higher intake of white rice and increasing risk of diabetes

Competing interests: All authors have completed the Unified Competing Interest form at www.icmje.org/coi_disclosure.pdf (available on request from the corresponding author) and declare: no support from any organisation for the submitted work; no financial relationships with any organisations that might have an interest in the submitted work in the previous three years; no other relationships or activities that could appear to have influenced the submitted work.

Ethical approval: Not needed.

Data sharing: No additional data available.

1 Fuller D, Sato Y-I, Castillo C, Qin L, Weisskopf A, Kingwell-Banham E, et al. Consilience of genetics and archaeobotany in the entangled history of rice. Archaeological and Anthropological Sciences 2010;2:115-31.

2 Higham C, Lu TLD. The origins and dispersal of rice cultivation. Antiquity 1998;72:867-77.

3 Liu L, Lee G-A, Leping J, Juzhong Z. Evidence for the early beginning (c 9000 cal BP) of rice domestication in China: a response. The Holocene 2007;17:1059-68.

4 Miller G, Prakash A, Decker E. Whole-grain foods in health and disease. American Association of Cereal Chemists, 2002.

5 Nanri A, Mizoue T, Noda M, Takahashi Y, Kato M, Inoue M, et al. Rice intake and type 2 diabetes in Japanese men and women: the Japan Public Health Center-based Prospective Study. Am J Clin Nutr 2010:92:1468-77.

6 Economic Research Service, United States Department of Agriculture. Data sets. 2010 www.ers.usda.gov/Data/

7 Villegas R, Liu S, Gao YT, Yang G, Li H, Zheng W, et al. Prospective study of dietary carbohydrates, glycemic index, glycemic load, and incidence of type 2 diabetes mellitus in middle-aged Chinese women. Arch Intern Med 2007;167:2310-6.

8 Foster-Powell K, Holt SH, Brand-Miller JC. International table of glycemic index and glycemic load values: 2002. Am J Clin Nutr 2002;76:5-56.

9 Salmeron J, Ascherio A, Rimm EB, Colditz GA, Spiegelman D, Jenkins DJ, et al. Dietary fiber, glycemic load, and risk of NIDDM in men. Diabetes Care 1997;20:545-50.

10 Salmeron J, Manson JE, Stampfer MJ, Colditz GA, Wing AL, Willett WC. Dietary fiber, glycemic load, and risk of non-insulin-dependent diabetes mellitus in women. JAMA 1997;277:472-7.

11 Schulze MB, Liu S, Rimm EB, Manson JE, Willett WC, Hu FB. Glycemic index, glycemic load, and dietary fiber intake and incidence of type 2 diabetes in younger and middle-aged women. Am J Clin Nutr 2004;80:348-56.

12 Hodge AM, English DR, O'Dea K, Giles GG. Glycemic index and dietary fiber and the risk of type 2 diabetes. Diabetes Care 2004;27:2701-6.

13 Sun Q, Spiegelman D, van Dam RM, Holmes MD, Malik VS, Willett WC, et al. White rice, brown rice, and risk of type 2 diabetes in US men and women. Arch Intern Med 2010;170:961-9.

14 Altman DG, Bland JM. Interaction revisited: the difference between two estimates. BMJ 2003;326:219.

15 Egger M, Davey Smith G, Schneider M, Minder C. Bias in meta-analysis detected by a simple, graphical test. BMJ 1997;315:629-34.

16 Harrell FE. Regression modeling strategies with applications to linear models, logistic regression and survival analysis. Springer-Verlag, 2001.

17 Greenland S, Longnecker MP. Methods for trend estimation from summarized dose-response data, with applications to meta-analysis. Am J Epidemiol 1992;135:1301-9.

18 Yu R, Woo J, Chan R, Sham A, Ho S, Tso A, et al. Relationship between dietary intake and the development of type 2 diabetes in a Chinese population: the Hong Kong Dietary Survey. Public Health Nutr 2011;Apr 5:1-9.

19 US Centers for Disease Control and Prevention. Incidence of diagnosed diabetes per 1,000 population aged 18-79 years, by age, United States, 1980-2009. 2012. www.cdc. gov/diabetes/statistics/incidence/fig3.htm.

20 Wild S, Roglic G, Green A, Sicree R, King H. Global prevalence of diabetes: estimates for the year 2000 and projections for 2030. Diabetes Care 2004;27:1047-53.
21 Agardh E, Allebeck P, Hallqvist J, Moradi T, Sidorchuk A. Type 2 diabetes incidence and socio-economic position: a systematic review and meta-analysis. Int $\mathrm{J}$ Epidemiol 2011:40:804-18.

22 Batres-Marquez SP, Jensen HH, Upton J. Rice consumption in the United States: recent evidence from food consumption surveys. J Am Diet Assoc 2009;109:1719-27.

23 Gu D, Reynolds K, Wu X, Chen J, Duan X, Reynolds RF, et al. Prevalence of the metabolic syndrome and overweight among adults in China. Lancet 2005:365:1398-405.

24 Hayashino Y, Yamazaki S, Nakayama T, Sokejima S, Fukuhara S. The association between socioeconomic status and prevalence of diabetes mellitus in rural Japan. Arch Environ Occup Health 2010;65:224-9

25 Murakami K, Sasaki S, Takahashi Y, Okubo H, Hosoi Y, Horiguchi H, et al. Dietary glycemic index and load in relation to metabolic risk factors in Japanese female farmers with traditional dietary habits. Am J Clin Nutr 2006:83:1161-9.

26 Barclay AW, Petocz P, McMillan-Price J, Flood VM, Prvan T, Mitchell P, et al. Glycemic index, glycemic load, and chronic disease risk-a meta-analysis of observational studies. Am J Clin Nutr 2008;87:627-37.

27 Nanri A, Mizoue T, Yoshida D, Takahashi R, Takayanagi R. Dietary patterns and A1C in Japanese men and women. Diabetes Care 2008;31:1568-73.

28 Larsen HN, Christensen C, Rasmussen OW, Tetens IH, Choudhury NH, Thilsted SH, et al. Influence of parboiling and physico-chemical characteristics of rice on the glycaemic index in non-insulin-dependent diabetic subjects. Eur J Clin Nutr 1996;50:22-7.

29 Larsen HN, Rasmussen OW, Rasmussen PH, Alstrup KK, Biswas SK, Tetens I, et al. Glycaemic index of parboiled rice depends on the severity of processing: study in type 2 diabetic subjects. Eur J Clin Nutr 2000;54:380-5.

30 Miller JB, Pang E, Bramall L. Rice: a high or low glycemic index food? Am J Clin Nutr 1992:56:1034-6.

31 Slavin JL, Martini MC, Jacobs DR Jr, Marquart L. Plausible mechanisms for the protectiveness of whole grains. Am J Clin Nutr 1999;70(suppl 3):459-63S.

32 Meyer KA, Kushi LH, Jacobs DR Jr, Slavin J, Sellers TA, Folsom AR. Carbohydrates, dietary fiber, and incident type 2 diabetes in older women. Am J Clin Nutr 2000;71:921-30.

33 Schulze MB, Schulz M, Heidemann C, Schienkiewitz A, Hoffmann K, Boeing H. Fiber and magnesium intake and incidence of type 2 diabetes: a prospective study and meta-analysis. Arch Intern Med 2007;167:956-65.

34 Song $\mathrm{Y}, \mathrm{He}$ K, Levitan EB, Manson JE, Liu S. Effects of oral magnesium supplementation on glycaemic control in type 2 diabetes: a meta-analysis of randomized double-blind controlled trials. Diabet Med 2006;23:1050-6.

35 Van Dam RM, Hu FB, Rosenberg L, Krishnan S, Palmer JR. Dietary calcium and magnesium, major food sources, and risk of type 2 diabetes in US black women. Diabetes Care 2006;29:2238-43.

36 Weickert MO, Mohlig M, Schofl C, Arafat AM, Otto B, Viehoff H, et al. Cereal fiber improves whole-body insulin sensitivity in overweight and obese women. Diabetes Care 2006;29:775-80.

37 Jang Y, Lee JH, Kim OY, Park HY, Lee SY. Consumption of whole grain and legume powder reduces insulin demand, lipid peroxidation, and plasma homocysteine concentrations in patients with coronary artery disease: randomized controlled clinical trial. Arterioscler Thromb Vasc Biol 2001;21:2065-71.

38 Zhang G, Pan A, Zong G, Yu Z, Wu H, Chen X, et al. Substituting white rice with brown rice for 16 weeks did not substantially affect metabolic risk factors in middle-aged Chinese men and women with diabetes or a high risk for diabetes. J Nutr 2011;141:1685-90.

39 Popkin BM. The nutrition transition in low-income countries: an emerging crisis. Nutr Rev 1994;52:285-98.

Accepted: 19 January 2012

\section{Cite this as: BMJ 2012;344:e1454}

This is an open-access article distributed under the terms of the Creative Commons Attribution Non-commercial License, which permits use, distribution, and reproduction in any medium, provided the original work is properly cited, the use is non commercial and is otherwise in compliance with the license. See: http://creativecommons.org/licenses/bync/2.0/ and http://creativecommons.org/licenses/by-nc/2.0/legalcode. 


\section{Tables}

\begin{tabular}{|c|c|c|c|}
\hline Author & Study participants & $\begin{array}{l}\text { Follow-up period and person } \\
\text { time }\end{array}$ & Exposure and assessment method \\
\hline Hodge et al 2004 & $\begin{array}{l}\text { Melbourne Collaborative Cohort Study: total }=31 \\
641 ; \text { cases }=365 ; 41.1 \% \text { male; age } 40-69 \text { years; } \\
\text { Melbourne, Australia }\end{array}$ & $\begin{array}{l}\text { Follow-up } 4 \text { years; } 129190 \\
\text { person years* }\end{array}$ & $\begin{array}{l}\text { Cooked rice assessed by FFQ consisting of } 121 \text { food } \\
\text { items. Reproducibility and validity of rice intake } \\
\text { assessments: NA }\end{array}$ \\
\hline Villegas et al 2007 & $\begin{array}{l}\text { Shanghai Women's Health Study: total=64 191; } \\
\text { cases=1608; } 100 \% \text { female; age } 40-70 \text { years; } \\
\text { Shanghai, China }\end{array}$ & $\begin{array}{l}\text { Follow-up } 5 \text { years; } 297755 \\
\text { person years }\end{array}$ & $\begin{array}{l}\text { Raw rice assessed by FFQ consisting of } 77 \text { food items. } \\
\text { Validation study for rice intake assessments: } 191 \\
\text { Chinese women; correlation coefficient }(r) \text { for } \\
\text { reproducibility } 0.49 \text { between } 2 \text { FFQs administered } 1 \text { year } \\
\text { apart; } r \text { for validity } 0.66 \text { between second FFQ and } 24 \\
\text { hour recall assessments }\end{array}$ \\
\hline Sun et al 2010 & $\begin{array}{l}\text { Health Professionals Follow-up Study: total }=39 \\
765 ; \text { cases }=2648 ; 100 \% \text { male; age } 32-87 \text { years; } \\
\text { United States }\end{array}$ & $\begin{array}{l}\text { Follow-up } 20 \text { years; } 702920 \\
\text { person years }\end{array}$ & $\begin{array}{l}\text { Cooked rice assessed by FFQ consisting of } 116-131 \\
\text { food items. Validation study for rice intake assessments: } \\
127 \text { Health Professionals Follow-up Study participants; } \\
r \text { for reproducibility } 0.52 \text { between } 2 \text { FFQs administered } \\
1 \text { year apart; } r \text { for validity } 0.53 \text { between second FFQ and } \\
\text { diet record assessments }\end{array}$ \\
\hline Sun et al 2010 & $\begin{array}{l}\text { Nurses' Health Study: total }=69120 \text {; cases }=5500 \\
100 \% \text { female; age } 37-65 \text { years; United States }\end{array}$ & $\begin{array}{l}\text { Follow-up } 22 \text { years; } 1404373 \\
\text { person years }\end{array}$ & Same as above \\
\hline Sun et al 2010 & $\begin{array}{l}\text { Nurses' Health Study II: total=88 343; } \\
\text { cases=2359; } 100 \% \text { female; age } 26-45 \text { years; } \\
\text { United States }\end{array}$ & $\begin{array}{l}\text { Follow-up } 14 \text { years; } 1210903 \\
\text { person years }\end{array}$ & Same as above \\
\hline Nanri et al 2010 & $\begin{array}{l}\text { Japan Public Health Center-based Prospective } \\
\text { Study: total=25 666; cases=625; } 100 \% \text { male; } \\
\text { age } 45-75 \text { years; Japan }\end{array}$ & $\begin{array}{l}\text { Follow-up } 5 \text { years; } 128330 \\
\text { person years } \dagger\end{array}$ & $\begin{array}{l}\text { Cooked rice assessed by FFQ consisting of } 147 \text { food } \\
\text { items. Validation study for rice intake assessments: No } \\
\text { of participants unknown; } r \text { for reproducibility } 0.69 \\
\text { between } 2 \text { FFQs administered } 1 \text { year apart; } r \text { for validity } \\
0.55 \text { between FFQ and diet record assessments }\end{array}$ \\
\hline Nanri et al 2010 & $\begin{array}{l}\text { Japan Public Health Center-based Prospective } \\
\text { Study: total=33 622; cases }=478 ; 100 \% \text { female; } \\
\text { age } 45-75 \text { years; Japan }\end{array}$ & $\begin{array}{l}\text { Follow-up } 5 \text { years; } 168110 \\
\text { person years } \dagger\end{array}$ & Same as above \\
\hline
\end{tabular}

$\mathrm{FFQ=food} \mathrm{frequency} \mathrm{questionnaire;} \mathrm{NA}=$ not available.

*Data provided by study investigators as requested.

†Person time estimated by multiplying number of participants by average follow-up time. 
Table 2/ Characteristics of prospective studies of white rice intake in relation to incident type 2 diabetes: outcomes, relative risks, and covariates

\begin{tabular}{|c|c|c|c|}
\hline Study & Study outcome and ascertainment & $\begin{array}{l}\text { Comparison categories and corresponding } \\
\text { relative risk }(95 \% \mathrm{Cl})\end{array}$ & Covariates in fully adjusted model \\
\hline Hodge et al 2004 & $\begin{array}{l}\text { Type } 2 \text { diabetes identified through self } \\
\text { reports; } 83 \%(303 / 365) \text { cases } \\
\text { confirmed by medical practitioners }\end{array}$ & $\begin{array}{l}<23 \text { g/day }{ }^{*} \dagger: 1.0 \text { (referent); } 23-32 \text { g/day: } 0.77 \\
(0.56 \text { to } 1.07) ; 33-55 \text { g/day: } 0.91 \text { (0.67 to } 1.22) \\
\geq 56 \text { g/day: } 0.93 \text { ( } 0.68 \text { to } 1.27)\end{array}$ & $\begin{array}{l}\text { Age, sex, country of birth, physical activity, family } \\
\text { history of diabetes, alcohol, total energy intake, } \\
\text { education, } 5 \text { year weight change, body mass } \\
\text { index, and waist:hip ratio }\end{array}$ \\
\hline Villegas et al 2007 & $\begin{array}{l}\text { Type } 2 \text { diabetes identified through self } \\
\text { reports; American Diabetes } \\
\text { Association } 1997 \text { diagnostic criteria }\end{array}$ & $\begin{array}{l}<500 \text { g/day } \ddagger: 1.0 \text { (referent); } 500-622 \text { g/day: } 1.04 \\
\text { (0.86 to } 1.25) ; 623-749 \text { g/day: } 1.29 \text { (1.08 to } 1.54) ; \\
\geq 750 \text { g/day: } 1.78 \text { ( } 1.48 \text { to } 2.15)\end{array}$ & $\begin{array}{l}\text { Age, body mass index, waist:hip ratio, smoking } \\
\text { status, alcohol consumption, physical activity, } \\
\text { income level, education level, occupation, } \\
\text { diagnosis of hypertension, and total energy }\end{array}$ \\
\hline $\begin{array}{l}\text { Sun et al 2010; Health } \\
\text { Professionals } \\
\text { Follow-up Study }\end{array}$ & $\begin{array}{l}\text { Type } 2 \text { diabetes identified through self } \\
\text { reports and confirmed by validated } \\
\text { supplementary questionnaire; National } \\
\text { Diabetes Data Group (before 1998) } \\
\text { and American Diabetes Association } \\
1997 \text { (after 1998) diagnostic criteria }\end{array}$ & $\begin{array}{l}<5.3 \mathrm{~g} / \text { day†: } 1.0 \text { (referent); } 5.3-15.8 \mathrm{~g} / \text { day: } 1.09 \\
(0.96 \text { to } 1.24) ; 15.9-45.0 \mathrm{~g} / \text { day: } 1.07 \text { (0.93 to } 1.23) ; \\
45.1-112.9 \mathrm{~g} / \text { day: } 1.30(1.12 \text { to } 1.50) ; \geq 112.9 \\
\text { g/day: } 1.02 \text { ( } 0.77 \text { to } 1.34)\end{array}$ & $\begin{array}{l}\text { Age; ethnicity (white, African-American, Hispanic, } \\
\text { and Asian); body mass index; smoking status; } \\
\text { alcohol intake; multivitamin use; physical activity; } \\
\text { family history of diabetes; total energy; intakes } \\
\text { of red meat, fruits and vegetables, whole grains, } \\
\text { and coffee }\end{array}$ \\
\hline $\begin{array}{l}\text { Sun et al 2010; Nurses' } \\
\text { Health Study }\end{array}$ & Same as above & $\begin{array}{l}<5.3 \mathrm{~g} / \text { dayt: } 1.0 \text { (referent); } 5.3-15.8 \mathrm{~g} / \text { day: } 1.00 \\
(0.90 \text { to } 1.11) ; 15.9-45.0 \mathrm{~g} / \text { day: } 1.07 \text { (0.96 to } 1.20) \\
45.1-112.9 \text { g/day: } 1.09 \text { (0.97 to } 1.23) ; \geq 112.9 \\
\text { g/day: } 1.11 \text { ( } 0.87 \text { to } 1.43)\end{array}$ & $\begin{array}{l}\text { Same as above, plus further adjustments for } \\
\text { postmenopausal status, hormone use, and oral } \\
\text { contraceptive use }\end{array}$ \\
\hline $\begin{array}{l}\text { Sun et al 2010; Nurses' } \\
\text { Health Study II }\end{array}$ & Same as above & $\begin{array}{l}<5.3 \mathrm{~g} / \text { dayt: } 1.0 \text { (referent); } 5.3-15.8 \mathrm{~g} / \text { day: } 0.93 \\
\text { (0.81 to } 1.07) ; 15.9-45.0 \mathrm{~g} / \text { day: } 0.94 \text { (0.81 to } 1.10) \\
45.1-112.9 \mathrm{~g} / \text { day: } 0.95(0.81 \text { to } 1.11) ; \geq 112.9 \\
\text { g/day: } 1.40 \text { ( } 1.09 \text { to } 1.80)\end{array}$ & Same as above \\
\hline $\begin{array}{l}\text { Nanri et al } 2010 \\
\text { (males) }\end{array}$ & $\begin{array}{l}\text { Type } 2 \text { diabetes identified through self } \\
\text { reports and confirmed by medical } \\
\text { records; Japan Diabetes Society } 1982 \\
\text { diagnostic criteria }\end{array}$ & $\begin{array}{l}0-315 \text { g/day: } 1.00 \text { (referent); } 315-420 \text { g/day: } 1.24 \\
(1.00 \text { to } 1.55) ; 420-560 \text { g/day: } 1.25 \text { (0.93 to } 1.67) \\
>560 \text { g/day: } 1.19 \text { (0.85 to } 1.68)\end{array}$ & $\begin{array}{l}\text { Age; study area; smoking status; alcohol } \\
\text { consumption; family history of diabetes mellitus; } \\
\text { total physical activity; history of hypertension; } \\
\text { occupation; total energy intake; intakes of } \\
\text { calcium, magnesium, fibre, fruit, vegetables, fish, } \\
\text { coffee, bread, and noodles; and body mass index }\end{array}$ \\
\hline $\begin{array}{l}\text { Nanri et al } 2010 \\
\text { (females) }\end{array}$ & Same as above & $\begin{array}{l}0-278 \mathrm{~g} / \text { day: } 1.00 \text { (referent); } 280-417 \mathrm{~g} / \text { day: } 1.15 \\
\text { (0.85 to } 1.55) ; 420-420 \mathrm{~g} / \text { day: } 1.48 \text { (1.08 to } 2.02 \text { ); } \\
\geq 437 \mathrm{~g} / \text { day: } 1.65 \text { (1.06 to } 2.57 \text { ) }\end{array}$ & Same as above \\
\hline
\end{tabular}

*Data provided by study investigators as requested.

†Serving size of $158 \mathrm{~g}$ for cooked rice assumed.

‡Raw rice intake levels converted to cooked rice intake levels by multiplication by factor of $2.5^{7}$ 


\section{Figures}

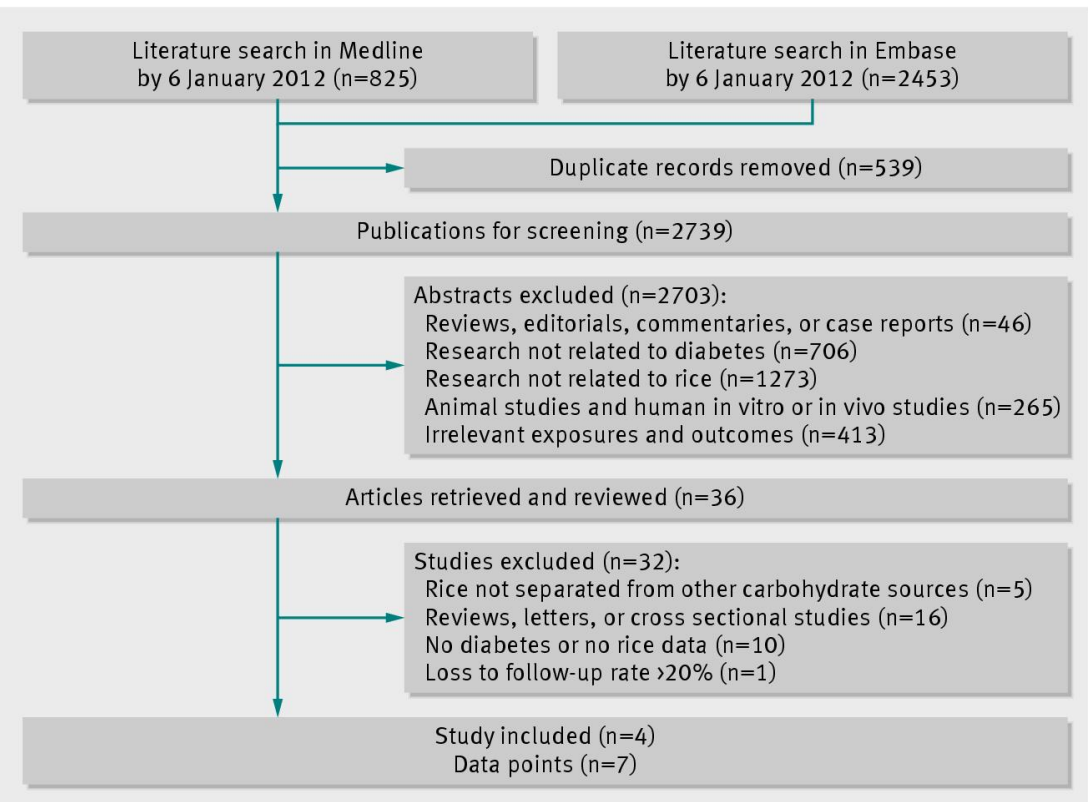

Fig 1 Literature search and study selection

\section{Study \\ Western population \\ Nurses' Health Study \\ Nurses' Health Study II \\ Health Professionals Follow-Up Study \\ Melbourne Collaborative Cohort Study \\ Subtotal: $\left.\right|^{2}=40.0 \%, P=0.172$}

\section{Asian population}

Japan Public Health Center-based Prospective Study (Men) Japan Public Health Center-based Prospective Study (Women) Shanghai Women's Health Study

Subtotal: $\left.\right|^{2}=51.6 \%, P=0.127$

Overall: $\left.\right|^{2}=72.2 \%, P=0.001$



0.5

Fig 2 Pooled random effects relative risk $(95 \% \mathrm{Cl})$ of type 2 diabetes comparing high with low white rice consumption levels. $P$ values are $P$ for heterogeneity 


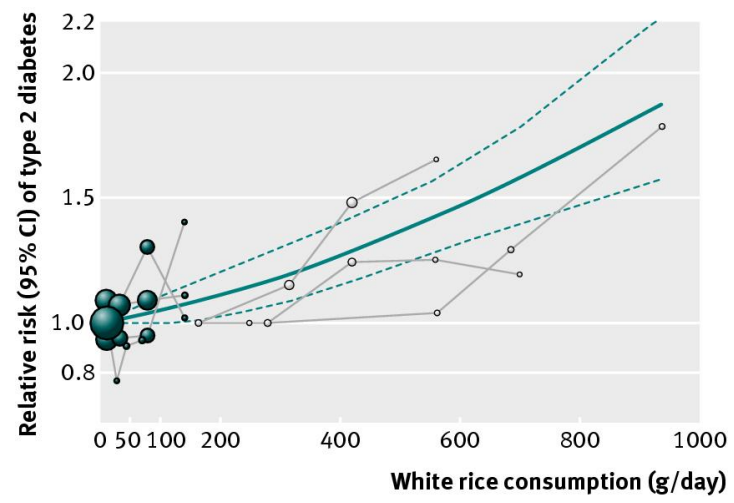

Fig 3 Dose-response relation between white rice intake and risk of type 2 diabetes. Solid line represents point estimates of association between white rice intake and diabetes risk; dashed lines are $95 \% \mathrm{Cls}$. Filled circles are relative risks corresponding to comparison categories in studies in Western populations; open circles are for studies in Asian populations. Size of circle is in proportion to sample size for each comparison group 